\title{
11
}

\section{Misreading the night: The shadows and light of a solar technology ${ }^{1}$}

\section{Chris Shepherd}

When Timor-Leste won independence, former resistance-leader-turnedstatesman, Xanana Gusmão, stated: 'our dream was to be self-governing, but now our dream is to develop, to become a developed nation' (RDTL 2002: 3). Since then, Timor-Leste's development industry has advanced a torrent of new ideas of what constitutes 'development'. It has brought to the Timorese people a dizzying mix of fantasies and propositions, sifting out the problems in 'tradition' and 'culture' that are perceived to present obstacles to development, and urging one or another form of intervention as 'solutions'. At the opposite end of the spectrum to fanciful, state-driven, high-modernity schemes (Meitzner Yoder 2015) has arisen a panoply of practical, small-scale non-governmental organisation (NGO)-led proposals to improve village and household services. Of these, solar technology has been favoured, not least for lighting rural areas beyond the reach of grid power. This chapter traces one such initiative in which an international NGO (INGO) contracted a national NGO to distribute solar lamps in the district enclave of Oecusse to replace 'suboptimal', mainly kerosene-based, lighting. Since I assessed the impacts of the program, the solar lamps are explored through my personal experience of evaluation and reporting. Through an analysis of the politics of

1 I thank Judith Bovensiepen, Alex Grainger and Ann Wigglesworth for their suggestions on a draft version of this chapter. I have refrained from citing reports or webpages to protect anonymity. 
knowledge, I show how the process of understanding the local experience of 'old' light and 'new' light was influenced by the NGOs in question. In particular, I explore my encounter with an institution that was reluctant to acknowledge the discrepancies between the 'real impacts' and what had initially been held out as the anticipated impacts of the solar lamps.

The mismatch between development's idealised futures and what happens in reality has been an enduring theme in the anthropology of development and 'post-development' literature (for example, Ferguson 1990; Sachs 1992). In the edgy world of performance-dependent funding, development institutions survive by strategically dealing with mismatches, seeking control over information and interpretations to avert criticism. Building on the idea that development has a 'front stage' and a 'backstage' (see Goffman 1959), which includes or excludes various audiences and perspectives through the generation of 'public' and 'hidden transcripts' (Scott 1992), I argue that the symbolic investment in imagined futures is so great that these futures continue to be propped up over time, even in the face of contradictory evidence. Institutions conceal their backstage 'shadow side' just as they strive to fashion a public, authoritative, expertisebased 'consensual community of knowers' to cloak their interventions in positive values (Mosse 2005).

Project evaluation undertaken by external consultants occupies a unique position in relation to these private-public dynamics. Not only do consultants have access to confidential knowledge, they also comprehend that their reporting influences broader perceptions, legitimacy and funding. In shaping project knowledge, evaluators must decide what to conceal (shadows) and what to reveal (light): they may highlight or ignore ambiguity in the data; raise or suppress counter-interpretations; acknowledge or overlook bungles; and report or ignore malpractice (see Ferguson 1997). In doing so, they navigate the boundary between the 'vision of the future' and what is empirically observed 'on the ground'. In some cases, however, explicit or tacit trade-offs between consultants and organisations ensure that consultancies remain favourable. In other cases, organisations conceal certain situations from evaluators, impress upon them the privacy of information or edit their documents (Crush 1995).

Bringing the 'anthropology of light' (Bille and Sorensen 2007) to bear on the 'new ethnography of aid' (Mosse 2005), the following account of project evaluation shows how my assessment of the solar-lamp initiative was compromised by a 'promised future' of what improved 
light would mean for beneficiaries. I became implicated in the shadows of both aforementioned institutions (the NGO and the INGO) when I began to modify research methods, raise doubts over received wisdom and draw attention to questions of ethics. I was equally enrolled in the 'promotional light' - namely, the auspicious internet-based, public relations (PR) campaign of the INGO. At stake was an 'imaginary of light': a culturally specific set of representations, images, signs and metaphors, with hierarchical values placed on the darkness and lightness of pasts, presents and futures (cf. Mahmud 1999). The imaginary of light had assembled a vision of 'the beneficiary' as benefiting in set ways, of the NGOs as transparent, philanthropic actors and of the solar lamps as life-changing technology; implicit, too, was the association of darkness with the underdeveloped past and present, and light with progress and modernity (see Kammen, Chapter 1; and Palmer, Chapter 10) Behind the investment in what is presented below as a misreading of the Oecusse lightscape, we see yet another expression of the general determination of development organisations of all types to secure their reputations and funding sources.

\section{The vision of the Radiant Nights program}

Grace Foundation (GF) was founded in 2010 by two individuals who came to believe that the simplest and best technologies for the so-called developing world were not reaching isolated people. Working with local partner organisations, GF's proposal was to introduce water filters, rolling drum water transporters and drip-irrigation systems to places that were the most remote and to people most in need. The organisation's technology of choice, however, was a kind of solar lantern called d.lights; just as these had been brought to Indonesia, the Philippines and India, they were also tried on Timor-Leste's Ataúro island and in Oecusse. The initiative was called Radiant Nights.

Radiant Nights was not all technology in the material sense. The ideas that travelled with the technology were equally important. The intervention adapted common development imaginaries of poverty to the harsh living conditions of Timor-Leste, where people depended on subsistence agriculture and fishing. Specifically, the targeted recipients were said to suffer from 'energy poverty', the rationale for which began with the absence of grid power. In Oecusse, the grid radiated out unevenly for several kilometres from the district capital, Pante Makassar, beyond 
which 60,000 people used kerosene lamps, candles, battery flashlights, firelight and moonlight. For want of better lighting, women were said to cook in relative darkness, certain livelihood activities were restricted to the daytime, children could not study properly at night and incomegenerating activities were hampered. The common kerosene lamps were described as especially problematic because they shed a dim light, blew out in the wind, caused house fires, emitted toxic smoke and taxed the scant economic resources of rural people.

Radiant Nights foresaw a growing collective of beneficiaries no longer reliant on dim, costly, dangerous, unhealthy and antiquated kerosene, candle or other lighting. Instead, they would receive bright, cheap, safe, salubrious, efficient, modern d.lights. The lamps would facilitate all the activities that development specialists presumed poor people without much light should be doing more of at night, and by better light: studying and learning; cooking and weaving; fishing and farming. The positive impacts of brighter light would include more money, more education, more security, more happiness and better health. This 'public transcript' of a gloomy present and a brighter future was already in place when d.lights were first shipped in. Local partner organisations repeated the imaginary, and the same ideas were conveyed to prospective beneficiaries in information sessions when distribution commenced. Notions of what a brighter future would mean, one could say, had been inscribed onto the technology.

The imaginary of Radiant Nights was consolidated over successive evaluations and impact assessments. Posted on GF's webpage, reports made concrete what had already been held out as a brighter d.light future. A before-and-after survey structure allowed for the contrast of baseline and follow-up figures. General progress narratives gave way to precise data and statistics. Bar graphs, pie charts and histograms lent visual clarity and exactitude to what had been promises and potentials. The reduction in kerosene-based and other lighting was specified to a tenth of a decimal point, and increases in average times spent attending to livestock or studying at night were calculated to the minute. The apparently unequivocal evidence based on such figures was boosted by photographs depicting the various uses of d.lights and the indubitable testimony of local people. 'Off-the-shelf' development narratives were also readily deployed to confirm the benefits of d.lights. Narrative logic was sometimes oxymoronic; for instance, d.lights were said to redress gender inequality as it was supposed that women were burdened by a greater share of the 
nightly household labour. Equally important to the imaginary were narratives and metaphors that underlined the altruistic character of GF, its donors and local partner organisations. Indeed, publicising that their high subsidies had reduced d.light prices to a quarter of the market value reinforced this humanitarian idea.

\section{Becoming a technology impact evaluator}

GF gave funding and guidance for assessors or 'fellows' to undertake evaluations of the initiative. Among other things, an interest in solar technology led me to accept GF's consultancy offer. The reports of four previous assessors, an established survey method and the optimism surrounding the initiative became my inheritance when I arrived at GF's head office in Singapore in May 2013, as the fifth GF assessor to be sent to Timor-Leste. I was introduced to those I would be reporting to and to the artefacts I would be examining: the disk-like S-1 (lampu kabuar), the cylindrical S-10 (lampu a'as) and the durable S-250 (lampu bo'ot). My tasks were to conduct surveys (with the local partner's support), write a series of public blogs and a final technology impact report (to be posted on GF's website), check that distribution and pricing were fair, and find out why d.lights had turned up across the border in Indonesian West Timor, where no such program existed.

A few days later, I was in Oecusse meeting GF's partner organisation, Sustainability Now And Forevermore (henceforth SNAF), the dozen staff of which ran programs in health and adult literacy. GF's partnership with SNAF had begun in late 2010 and, since then, 6,000 d.lights had entered the enclave. GF also covered the wages of two SNAF staff. As stipulated by contract, SNAF was permitted a mark-up of around 15 per cent to its own targeted groups, and slightly more for individuals purchasing a limited number of lamps directly from the office. According to the SNAF director, the subsidised sale price of d.lights was as it should be (between US\$6 and US\$14 for the three models), but 'some naughty people' had come to the office, claiming to represent a group, had purchased many boxes of d.lights and sold them on at higher prices. Evidently, approximately a hundred d.lights had crossed the border to Indonesia at Melihat (near Passabe). 
SNAF showed no enthusiasm for my technology assessment. The director suggested that his staff do the surveys so I could relax on the beach. Insisting on doing the surveys myself, and reminding him of the arrangement that transport would be made available, the director eventually agreed to lend me his personal motorbike. This, however, was the extent of SNAF support: no details about how many d.lights had gone where were available; my request to tag along with staff in the routine distribution of d.lights could not be met because d.lights were apparently out of stock; and a staff member could not be spared to help me with the surveys. So I took to exploring Oecusse's four subdistricts and 18 (or so) villages on my own. From the main routes that connected Pante Makassar to Sakatu (the eastern border with Indonesia), Citrana (western border), Oesilo (southern border) and Passabe (southwestern border), I followed tracks at random. When spotting the bright red d.lights recharging in the sun, I would seek out the owners for surveying.

I soon noticed major discrepancies in pricing. The lamps had been fetching twice, treble or quadruple their subsidy price inside Oecusse and, I would later find, up to tenfold their subsidy price on the Indonesian side of the border. In Oecusse, I made extensive enquiries in order to understand the channels and modes of lamp distribution from the SNAF office to a range of lowland and highland villages. I sought information on how lamps had been directly purchased from the SNAF office by traders or by UN workers, and at what price; which SNAF staff might have been implicated in private mark-ups, how much these mark-ups were, and when and where transactions took place; how lamps might have entered into formal or informal trading chains, and the degree to which successive sales inflated prices; and whether, how and for how much the director, independently of SNAF, had been selling d.lights through his family networks. I also sought to determine how previous evaluators might have been 'kept in the dark'; for example, if they might have been deliberately directed to places where subsidies had been respected (and not elsewhere). I provoked 'admissions' from SNAF staff as to how they or others might have been involved in unofficial d.light sales, and for how long certain distribution models might have been operating since the inception of Radiant Nights.

By combining direct testimony and personal observations, and then categorising and enumerating known instances of d.light sales and purchases, I assembled a perspective on how and when d.lights had been distributed by which actors, and at what prices. I also extrapolated from what I took to be a sufficient number of cases, to generalise about 
patterns of distribution. However, not everything could be quantified or was empirically straightforward. I considered the fact that SNAF, for example, was not a homogenous entity, that SNAF management and staff might be 'in collusion' on one front but 'in conflict' on another. It was not clear, moreover, exactly where to draw the line between 'unintentional mismanagement' and what some would interpret as 'wilful abuse of contract', as independent trading chains, not SNAF's sales, appeared to be elevating d.light prices to their highest levels; nor could I be certain who was responsible for taking d.lights across the border into Indonesia. This fact-finding effort led me to conclude that some elements within SNAF had been selling d.lights at various sites at inflated prices, even to UN workers, and that SNAF and other actors had turned subsidies into profits.

The director of SNAF, meanwhile, became incensed when he heard of my pricing probe. He called me to his office and confronted me. Nervously, I only acknowledged the possibility that certain SNAF staff might have been raising the price of d.lights behind his back, and that he would need to consider new accountability measures prior to the next delivery of lamps, which, I assured him, would soon be dispatched. The director recovered his composure-and me mine-and from then on attitudes changed: a staff member was ready to help with surveys; boxes of d.lights appeared from behind a locked door; and a 'socialisation session' was arranged for my viewing.

\section{Surveys and publicity}

I resumed the surveying with a SNAF staff member. The tried-andtested method sought information on the constitution of households (number, age, gender), household expenses, lighting methods and costs, and whether and why the various methods were valued, either positively or negatively. The survey also sought information on night-time activitieswho performed them, for how long, using which kind of light and user perceptions of the effectiveness of each. It asked how happy respondents were before and after d.lights, and to rate that happiness on a scale of 1 to 10 . I modified the survey by adding a raft of questions on income and assets. 
While the internal, 'backstage' correspondence with GF concerned the complex methods of distribution (to indict or exonerate SNAF, as the case may be), the information derived from the surveys (and the conversations that surrounded them) sufficed to build a 'front stage' of public blogs that appeared on GF's website for PR purposes. I succeeded in showing how much beneficiaries preferred the brighter light of d.lights over every other light, and I quantified the savings derived from an elimination of or reduction in regular outlay for kerosene, torch batteries and candles. The possession of two or three d.lights, I emphasised, was enough to do away with kerosene and other lighting-related purchases.

My blogs reported mini-case studies, such as one of a certain upland subsistence farmer named Domingas. Although I had been moved by the abject conditions of Domingas' bare existence, I was hardly aware at the time of the gap that opened up between my experience and feelings, on the one hand, and the detachment and calculation that went into my portrait of her, on the other. I made hers a story of forced relocation, personal misfortune, limited agricultural land and a solitary chicken to her name. After her husband had died at home (due to an untreated infection) leaving her alone with two children, she had to make do with an annual income of US $\$ 100$. Online went a photograph of a painfully thin, unkempt Domingas posing with a d.light in her hand. I described how d.lights had made an appreciable difference to Domingas' life, permitting her an annual saving of US\$50. 'Rice, not kerosene, was now her single largest expense', and Domingas was happy because 'she didn't have to sit in the dark anymore'.

Another of my blogs covered the lowland household of the Ulans, a newly-wed couple that, thanks to a micro-credit scheme, had opened three roadside businesses: a grocery store, a garage and a carpentry workshop. Within a few years, their annual income had shot up from almost nothing to a couple of thousand dollars. The blog related to an international audience a story of successful entrepreneurship in which d.lights had played a pivotal role: the acquisition of three in 2010 had set the Ulans back a mere US\$30, but had saved them US\$400 a year in 'old' lighting costs. I proposed that d.lights had been a driving force behind this young family's upward mobility, as well as their very transition from a near-subsistence household, as it was then, to a semi-subsistence household, as it was now. 
These stories were not 'untrue'. And yet I took for granted that they were contrived, front-stage compositions designed to maximise the perceived value of d.lights through the construction of 'promotion subjects'. I would spend the mornings in Oecusse's sole café crafting the sketches, interweaving development, poverty and happiness logics with anecdotes and testimony. The sketches showed that what had once been held out as the 'promised future' of d.lights had materialised. The grounding of these stories in a careful selection of 'the facts' made them credible. However, nobody but me could have known that, of all possible cases, I had highlighted the cases of Domingas and the Ulans because they most graphically illustrated the messages I intended to transmit. Also relegated to the backstage was information about the real cost of d.lights, doubts over reported household expenses and incomes, and impacts on local kerosene traders. That the Ulans were about to upgrade to a solar system with a fixed roof-top panel was not quite an accidental oversight. My all-positive, reductive accounts betrayed the complexity of Timorese livelihoods and the actual role of d.lights therein.

Some of the blogs made their way to ETAN (East Timor \& Indonesia Action Network) and other online fora. I drew vain satisfaction from being on the inside celebrating development as opposed to the outside critiquing it. I could not see how anthropological critiques of development applied to the case at hand (Hobart 1993; Meitzner Yoder 2015). I had no concerns about the contrived nature of the d.light stories because in my mind the end justified the means. The real-life 'use value' of the d.lights, after all, was many times greater than the 'purchase value', as I observed through experiment when I unsuccessfully tried to acquire d.lights from their owners at US\$100 apiece.

\section{A change of method}

As my enthusiasm for d.lights grew, my confidence in the survey method crumbled. I felt frustrated by the routine nature of surveying, I questioned the accuracy of responses and was disconcerted by their predictability. The surveys did support what would have been obvious without surveys; namely, that the people preferred d.lights and saved money through a lesser reliance on 'old' lighting. But beyond that I doubted the surveys could provide 'data' reflecting Timorese experience. It seemed, rather, that they mirrored the development industry's need for disposable PR-oriented information through a method that lent itself to quantification. 
On page two of the survey sheet, for example, came the question about activities - exactly which ones did d.lights light up? There were five boxes to fill in with activities, below which came two rows of boxes in which to jot down how many people in the household performed these activities and how long they spent doing them. My question 'what activities do you use d.lights for?' usually returned a blank stare. So, I would prompt my interlocutors: 'Cooking?'; 'Eating?'; 'Washing dishes?'; 'Children's study?'. As for how long they performed these activities each night, my guess was as good as theirs. So the surveys proceeded from one prompted activity to the next as I tried to come up with original prompts.

Needless to say, reflecting on activities, accounting for time and rating happiness were foreign to the respondents. I was worried by the poverty of the data and their eventual, and expected, translation into precise figures of how, when and for how long d.lights were employed. I wondered why d.lights could not be studied as ethnographers would study a spear or a hoe, by following it for some time and watching how the technology is woven into social life. Realising that surveys were more suited to understanding the social life of surveys than the social life of d.lights, I resolved to switch from day shift to night shift. To avoid sitting in huts night after night, I would venture out on a series of night rides, stopping at every d.light I encountered, recording its specific use and making conversation with the owners.

So it happened that on Saturday, 15 June 2013, at 6.45 pm, I left Pante Makassar, riding west into the night along the coast towards Citrana. Just beyond the end of the power grid in Lifau, I chatted to a couple of men who were corralling the pigs with the aid of one S-250. Further along the road, I surprised a family under a d.light-lit verandah who, when asked what they were doing, professed to be 'only sitting'. Beyond the river, I met five people walking along the road with their d.light, who said they were going 'nowhere'. Rounding a curve in the road, I skidded to a halt at one d.light and four girls, who ran off screaming when I dug into my bag for my camera - 'research method needs further refinement', I jotted down in my notebook. Arriving at a village at $7.35 \mathrm{pm}$, I was advised not to stay out any longer for ninjas were about. Ninjas, I discovered, were tall figures, dressed all in black with big boots; they stole things and took children's heads, placing them under bridges. After observing d.light use in the village, I motored on towards Citrana in the pitch black, stopping only to photograph one man and two children on the beach scanning 
the rock pools for trapped fish with their d.light. The man issued a stern warning about ninjas. I rode on until the latent, shadowy presence of ninjas became too spooky.

I kept up the excursions for the next couple of weeks. I saw d.lights being used for all manner of activities - cooking, eating, weaving, fishing, threshing, shucking, washing, playing cards, looking for something (a cup), going somewhere, getting something or running away from someone. D.lights were also being used for shedding a lamp-light on my own activities, such as to determine who it was calling out at the gate, to complete a remaining survey, or to have my puncture mended in the dead of night. But still, my observations were limited to 'use'. One morning, I came across the words of Tim Ingold (2000: 253), who noted that we have become so intrigued by seeing that we have 'lost touch with the experience of light'. I resolved to glimpse beyond the pragmatic seeing or using d.light beneficiary to the one whose sensibility was imbued with light, shade, colour, glare or tint.

That night was windy and faintly starlit. The rice fields that caught my eye stretched across a plain between black mountains and grey sea. D.lights appeared as constellations of stars, by whose steady glow I navigated my way from the roadside, where I had parked, across an ocean of stubble. Stumbling along, I drew ever closer to the islands of light, of which one became my destination. Soon I was able to discern children's laughter, men's threshing banter, women's gaiety around the open fire, the scent of steaming maize and the drone of a threshing machine. All was suffused in soft light. My next blog read like this:

D.lights were suspended, perched or sitting in their places around the encampment ... This sheltered lightscape was a place of work, fun, conversation and cooking; children, too many to tell, tested that borderland between the light, bright and safe, and the lurking obscurity. The light illuminated men, who fed rice stalks to a grunting machine, and women who stoked the fire and stirred a pot. Shreds of husks blew away downwind, flickering like meteorites; upwind a small child slept on a tarpaulin, blanketed in blue. In the shadows, a woman, her back turned, breastfed; one curious toddler peered out at a stranger from behind her mother's legs; just beyond the circle of light, glowing eyes, perhaps a cat's, reminded us that we could be seen but we could not see them. Yet they could not enter because this defining light was ours, not theirs. 
Definitely, d.lights were being used for all sorts of activities. But equally importantly, I added in the blog, d.lights illuminated words, stories, laughter, tears, feelings, touch and furtive glances. They lent colour and clarity to exchanges, expressions and gestures. D.lights were helping to bring people together in socially meaningful and affective ways, to strengthen their bonds, enjoy each other's company, share cigarettes and reinforce their culturally shaped mode of being so they could better be that way at night under brighter light (see Bille and Sorensen 2007).

More than just practical lighting actants, d.lights could be read as subtle ontic modifiers of night-time being. D.lights even illuminated 'nonuse'. Children tended to sleep beside a burning d.light all night long, and another one would often be left lighting up the verandah after the grown-ups had turned in. D.light, perhaps, was the all-night light that made people feel safe - safe from prowlers, killers, spirits, ghosts, spooks, witches and ninjas. D.light was the only light that could realistically - dare one say economically - be left on to'o dadeer (until dawn), as most survey respondents had put it when asked how long they used their d.lights each night. Night-time observation put to'o dadeer into context.

\section{Misreading light and GF's editorial erasure}

Night research exposed oversights, inaccuracies and even fallacies that had been maintained through the daytime survey. One fallacy, in particular, stood out. A major selling point for Radiant Nights had been that children could now do their homework after the sun went down. Previous surveys, as well as my own, had borne out the fact that d.lights were driving a revolution in children's nocturnal study habits. Over the course of my night rides, however, I saw no kids studying. So where were all the diligent Oecusse kids doing their homework?

It became clear that this dedicated night-time village study did not take place under any kind of light, not even in broad daylight. Kids had no reason to study and no materials to study with. Why, then, did surveys tell us one thing and observation another? The survey's 'study' prompt was partly responsible. But behind the prompt, it seemed to me, lay development imaginaries and policy ideas constantly reiterated by the state and NGOs. What d.light recipients had not picked up through generalised policy dissemination, they had learned through 'socialisation sessions' that accompanied d.light acquisition. By the time people were responding to surveys, they already had a strong sense that children's 
evening study was highly valued and that saying 'yes' to study was the 'correct' answer - correct in the sense of imitating nation-building ideas of education and progress; to state otherwise, they knew, might have invited disapproval (see Shepherd 2004). 'What has failed us', read a draft blog:

is not so much the d.lights than the survey method itself. D.lights are therefore just part of the answer to a multifaceted problem, whose resolution must encompass improvements in school infrastructure, teacher professionalism, the availability of study materials and changes in village values.

The same draft blog continued that when the survey method produced fallacies there is much to be learned about ourselves and how the development industry shapes knowledge'. GF was troubled by the content of that blog. A coordinator contacted me suggesting that the children of Oecusse had perhaps put their books aside for the holidays.

GF would not have wanted to reveal to its benefactors how it shaped knowledge. Nor would it be inclined to recognise a more complex 'problem configuration', for that did not fit with the promotion of technologies that claimed exclusive rights over 'the solution' - the technology had to be a heroic actant. As both a 'vision of the future' and, subsequently, a demonstrated 'fact', GF had invested heavily in the proposition that d.lights alone would have and had had far-reaching impacts on children's study and, by extension, education and life chances; statistics, graphs, charts and testimony were all advanced as solid evidence. Could it be admitted that this had been a misinterpretation? That equivocal draft blog never found its way onto GF's website.

GF directed me to write the final technology impact assessment. Obligingly, I assembled the same bar graphs and pie charts as other evaluators had done, based on survey data that could not possibly have been accurate and that conferred a misleading authority on the otherwise mostly fair claims concerning the advantages of d.lights. I was told to present information on SNAF's sale of d.lights as an internal document ('Part B'), which I did. No public mention was ever made of GF's termination of partnership with SNAF. (That termination of partnership following my departure from Oecusse may or may not have resulted from my internal reporting.) By the time the technology impact assessment could be viewed online, all my praise for the initiative had been highlighted in bold font, but the inadequacies of the survey method and the program's negligible impacts on education had been erased from the executive summary. 


\section{Conclusion}

'Our' developer-visions of the future of 'developees' are inevitably expressed as 'their needs', even 'their wants', as if there were some universal rendition thereof (Shepherd 2004: 237). In practice, these needs and wants might be fully or partly fictitious projections, which then become 're-translated' and 'inscribed' in all manner of ways over the course of 'implementation', when they intersect with real local visions, practices and the contingencies of appropriation. The vision of the future inherent in Radiant Nights had many ramifications inside Timor: initiatives were operationalised, partner organisations enrolled, boxes unloaded, technology circulated and d.lights appropriated. Meanwhile, expert opinion was mobilised in the form of foreign evaluators to assess 'impacts' by way of an institutionalised survey method. That method served to confirm the originally anticipated outcomes, correlating expected impacts with actual impacts, and results were channelled into PR.

I then appeared as an evaluator, adopted and expanded the same method, and took to the optimisation of PR. The empirical method showed up all sorts of technology effects, which concerned 'use', but went far beyond it, covering a multitude of practical and affective engagements with the technology. However, the more empirical night-method, as well as a critical approach, showed up discrepancies - discrepancies between the real and purported modes of technology distribution, the real and purported suitability of the survey method, and the real and purported impacts. Then, the backstage was poised to absorb, deflect and conceal the mismatches. This backstage was mobilised precisely because 'the future' had been narrativised in a particular, vested way. The point is not simply that 'the future' failed to materialise as it was supposed to; rather, it is that the tension between the 'unrealised future' and 'reality' materialised all sorts of effects in the here and now in Timor-Leste and beyond, not least of which were the negotiations surrounding my impact assessment.

I may not have been a typical evaluator. Nevertheless, the case puts the spotlight on the otherwise hidden knowledge filters that produce the front and back stages that are activated in an ongoing relationship with future visions. These stages, I believe, structure all development theatres with an acute awareness of how particular initiatives have pictured and promoted a given future; the stages are deployed precisely to manipulate the perceptions of various audiences about 'the future' as it has been 
projected, anticipated or promised, at some time in the past, to legitimise and resource an intervention. Evaluators, for their part, are drawn into this impression management that casts shadows and light, even though their reporting generally poses as 'neutral'; neutrality itself is a frontstage artifice designed to deny the existence of the hidden transcripts of vested interests, personal desires and so on. None of this is new (see Ferguson 1997; Mosse 2005). If there is anything new to this chapter, it is the proximity of the author to the case at hand: a narrative about an evaluation experience has been formed by a critical ethnographer of development (me) who has had direct access to the subjective world of an evaluator (mine).

As I went about exposing the backstage of the less powerful SNAF and mostly fortifying the front stage of GF, I was doing my own stage work. This centred on matters of power and the web of relationships that I had to work within, as well as touching on various ethical conundrums (Visweswaran 1994). In writing this chapter, too, I remain bound to power relations and risks inherent in representation, particularly when legality is at issue. To be clear, I am not saying that the organisation called SNAF was 'corrupt'. (What one thinks privately is often a different matter.) The antagonistic, simplistic notions of 'corruption' and 'good governance' are context-dependent and interpretatively flexible in ways that defy the normative boundaries imposed by foreign developmentalism. The slippery slope of temptation, the life circumstances of development staff, the 'ordinary commercial impulses' of traders, and the balance of communalism, professional commitments, family obligations and self-interest of management itself, are some factors that contextualise the imported, good-versus-bad moral framework of the development industry.

To relate this personal tale of 'consultancy' to consultancy in general, I would argue that consultant evaluators can only assess 'real impacts' within institutional frameworks of knowledge management, the primary concern of which is to prevent 'visions of the future' from unravelling in a contingent local-development arena where interventions never proceed according to design. Put otherwise, evaluators embark on an orchestrated process of gathering information and representing situations that defend visions, converting 'projected needs' of subject peoples into a kind of institutional capital based on rehearsed demonstrations of positive impacts (Mosse 2005; Shepherd 2004). In my evaluation, I resisted the script at 
times, but, for the most part, I played the role. Perhaps there was nothing unusual about my 'consultancy experience' after all, except for the fact that I have now written a chapter on it.

In the act of illuminating one set of shadows - the NGO shadows of dubitable modes of distribution, of questionable impacts and of unsatisfactory methods - I have created another set of shadows since, by definition, a chapter such as this can only be a 'public transcript'. Were readers, for example, privy to previous drafts of this chapter or to the editorial deliberations concerning publishable content and appropriate style, they would uncover layers of hidden transcripts in these too. And more hidden transcripts and shadows lie behind the writing of this chapter as well as my experiences in Oecusse in Dili. As academics, researchers or development specialists (and, of course, development beneficiaries too), we are all moving between back and front stages, often uncomfortably aware of our back stage and, ideally, carefully managing the front. This chapter is no less a contrived front-stage performance than the PR portraits of the solar technology recipients in Oecusse - the conventions differ, but the shadows and light are the same.

\section{References}

Bille, M. and Sorensen, T. F. (2007) 'An anthropology of luminosity: The agency of light', Journal of Material Culture, vol. 12, no. 3, pp. 263-284. doi.org/ $10.1177 / 1359183507081894$.

Crush, J. (ed.) (1995) Power of development, London: Routledge.

Ferguson, J. (1990) The anti-politics machine: Development, depoliticization and bureaucratic power in Lesotho, Cambridge: Cambridge University Press.

Ferguson, J. (1997) 'Anthropology and its evil twin: "Development" in the constitution of a discipline', in Cooper, F. and Packard, R. M. (eds) International development and the social sciences. Essays on the history and politics of knowledge, Berkeley: University of California Press, pp. 150-175.

Goffman, E. (1959) The presentation of self in everyday life, Garden City: Doubleday Anchor Books.

Hobart, M. (ed.) (1993) An anthropological critique of development: The growth of ignorance, London: Routledge. 
Ingold, T. (2000) The perception of the environment: Essays on livelihood, dwelling and skill, London: Routledge. doi.org/10.4324/9780203466025.

Mahmud, T. (1999) 'Postcolonial imaginaries: Alternative development or alternatives to development?', Transnational Law and Contemporary Problems, vol. 9, no. 25, pp. 25-34. Available at: digitalcommons.law.seattleu.edu/cgi/ viewcontent.cgi? referer $=$ www.google. $\operatorname{com} / \&$ httpsredir $=1$ \&article $=1353 \&$ context $=$ faculty.

Meitzner Yoder, L. S. (2015) 'The development eraser: Fantastical schemes, aspirational distractions and high modern mega-events in the Oecusse Enclave, Timor-Leste', Journal of Political Ecology, vol. 22, pp. 299-321. Available at: jpe.library.arizona.edu/volume_22/Yoder2015.pdf. doi.org/ 10.2458/v22i1.21110.

Mosse, D. (2005) Cultivating development: An ethnography of aid policy and practice, London and Ann Arbor, MI: Pluto Press.

RDTL (Democratic Republic of Timor-Leste) (2002) Komisaun planu: Timor Lorosa'e 2020: Ita nia nasaun, ita nia futuru, Dili.

Sachs, W. (ed.) (1992) The development dictionary: A guide to knowledge and power, London and New Jersey: Zed.

Scott, J. C. (1992) Domination and the Arts of Resistance: Hidden Transcripts, New Haven: Yale University Press.

Shepherd, C. (2004) 'Agricultural hybridity and the "pathology" of traditional ways: The translation of desire and need in postcolonial development', Journal of Latin American and Caribbean Anthropology, vol. 9, no. 2, pp. 235-266. doi.org/10.1525/jlca.2004.9.2.235.

Visweswaran, K. (1994) Fictions of feminist ethnography, Minneapolis: University of Minnesota Press. 
This text is taken from The Promise of Prosperity: Visions of the Future in Timor-Leste, edited by Judith Bovensiepen, published 2018 by ANU Press, The Australian National University, Canberra, Australia.

doi.org/10.22459/PP.2018.11 